\title{
ANALISA MENINGKATNYA PEMAKAIAN OLI PADA ENGINE C7 EXCAVATOR 320D CATERPILLAR MENGGUNAKAN 8 STEP TROUBLESHOOTING (STUDI KASUS PT. KASONGAN BUMI KENCANA)
}

\author{
Lintar Hariyandi 1), Qomariyatus Sholihah ${ }^{2)}$, Achmad Kusairi Samlawi ${ }^{3)}$ \\ 1), 2), 3) Program Studi Teknik Mesin Fakultas Teknik Universitas Lambung Mangkurat \\ JL. Akhmad Yani Km.36 Banjarbaru, Kalimantan Selatan,70714 \\ Email : Lintarcaptain@gmail.com
}

\begin{abstract}
Excavator 320D using C7 engine. Based on the problems that have occurred in the engine C7 in one company that is engaged in coal mining in which the number of engine problems that occur due to frequent loss of oil or increased oil consumption in the engine (High Oil Consumption), Using 8 Step troubleshooting with the goal knowing the cause of increased use of oil in the Engine C7 Caterpillar 320D Excavator and, Knowing the impact of rising oil consumption of the engine components Caterpillar 320D Excavator C7, and Knowing the cost of losses due to increased oil consumption in the Engine C7 Caterpillar 320D Excavator. After analysis 8 step troubleshooting is known to cause increased oil consumption is excessive because of the use of air cleaner is not in accordance with the OMM (Operational Manual Maintenance applicable, the impact of increased oil consumption which These conditions lead to premature wear on the components and the cost of repair to the engine that experienced high oil consumption amounted Rp.309.056.768
\end{abstract}

Keyword : Excavator, Troubleshooting, Oil Consumption

\section{PENDAHULUAN}

Penggunaan alat berat atau heavy equipment akhir-akhir ini makin hari makin bertambah, ini disebabkan karena penggunaan alat berat dapat memudahkan pekerjaan baik itu dalam skala kecil maupun dalam skala besar. Alat berat adalah suatu alat yang dapat melakukan berbagai macam pekerjaan sesuai dengan aplikasinya. Penggunaan alat berat diberbagai pekerjaan dapat melakukan berbagai jenis pekerjaan di antaranya adalah pekerjaan industri, mining, construction, dan lain-lain. Salah satu merek alat berat ternama yang banyak digunakan dalam dunia kerja adalah Caterpillar, Caterpillar adalah salah satu perusahaan pembuat alat berat yang ada di Amerika. Tujuan dari penggunaan alat-alat berat tersebut adalah 
sjme KINEMATIKA VOL.2 NO.2, 1 Desember 2017, 67-82

untuk memudahkan manusia dalam mengerjakan pekerjaanya, sehingga hasil yang di harapkan dapat tercapai dengan lebih mudah dan dengan waktu yang lebih singkat. [1]

Seiring meningkatnya kompetisi industri global, keandalan suatu machine sangatlah diperlukan khususnya machine Excavator. Sumber tenaga awal pada unit terletak di engine yang di teruskan kekomponen. Selanjutnya dalam hal ini performance engine sangatlah harus benar - benar terjaga. Dari latar belakang yang sudah dijabarkan diatas, maka dari itu penulis mengambil judul tugas akhir tentang :Analisa Meningkatnya pemakaian Oli pada Engine C7 Excavator 320D Caterpillar menggunakan 8 Step Troubleshooting (Studi kasus PT. Kasongan Bumi Kencana).

\section{DASAR TEORI}

\section{Claim Oil Consumption}

Untuk claim oil consumption, Claim Story harus menunjukkan:

1. Rasio oil dan fuel consumption.

2. Penyebab dari oil consumption.

3. Kondisi komponen yang diperiksa untuk menentukan penyebab oil consumption.

\section{BSOC (Brake Spesifik Oil Consumption)}

Perhitungan dibawah ini merupakan cara yang digunakan untuk menentukan BSOC pada engine. Perbandingan dapat dilakukan antara operasi engine typical value pada engine tersebut. Engine pada service meter yang 
Tabel 1. Brake Spesifik Oil Consumtion

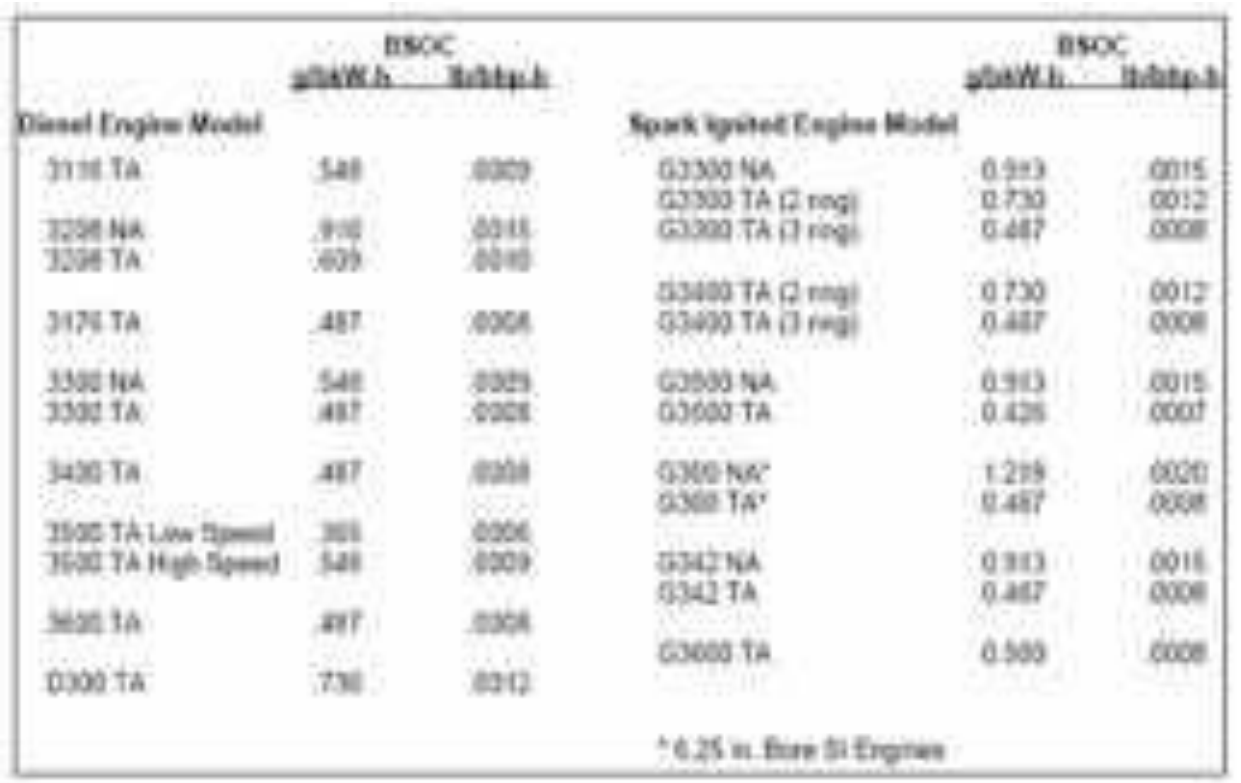

Sumber:Modul Engine Perfomance Analysis

masih sedikit memiliki oil consumption yang lebih rendah dari pada typical value dan engine dengan service meter yang banyak memiliki oil consumption lebih besar dari pada typical value, tetapi typical value tetap akan menjadi bahan pertimbangan untuk menentukan oil consumption. [4]

\section{Perhitungan BSOC}

Perhitungan dibawah ini merupakan cara yang digunakan untuk menentukan BSOC pada engine. Perbandingan dapat dilakukan antara operasi engine dan typical value pada engine tersebut. Engine dengan service meter yang masih sedikit memiliki oil consumption yang lebih rendah dari pada typical value dan engine dengan service meter yang banyak memiliki oil consumption lebih besar dari pada typical value, tetapi

\section{Menghitung Rata-Rata Oil Consumption}

Terdapat sebuah rumus yang digunakan untuk menghitung BSOC engine sehingga dapat memperkirakan rata-rata pemakaian oli pada engine. [4] 
sjme KINEMATIKA VOL.2 NO.2, 1 Desember 2017, 67-82

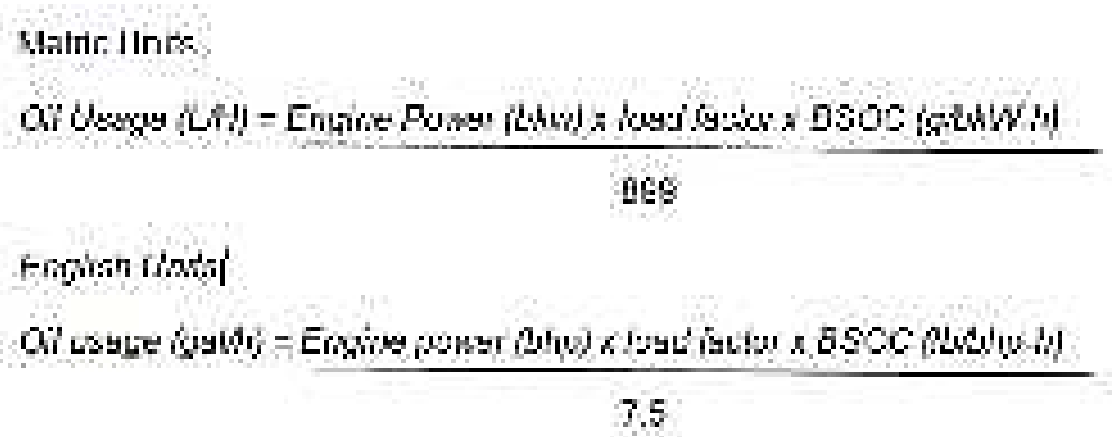

Sumber: ModulEngine Perfomance Analysis

\section{METODE PENELITIAN}

Dengan mempelajari masalah-masalah yang sering terjadi pada Engine C7 Excavator 320D Caterpillar. Kemudian penyebab masalah yang muncul dianalisa dengan cara mengumpulkan data-data, dari data tersebut dimunculkan akar dari permasalahan yang sering terjadi pada Engine C7 Excavator 320D Caterpillar. Langkah-langkah penelitian ditunjukkan pada diagram alir 


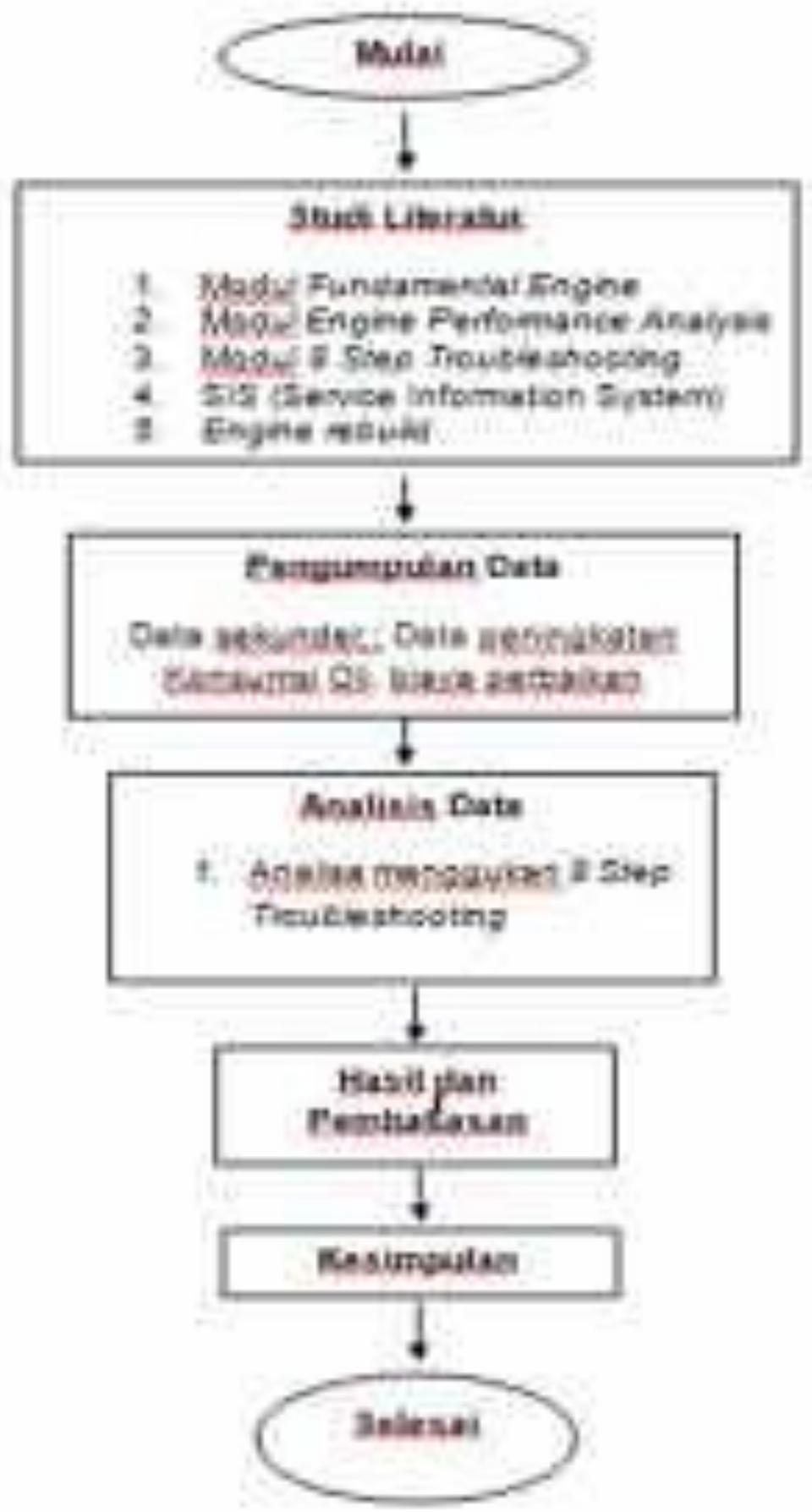

Gambar 1. Diagram Alir Penelitian 
sjme KINEMATIKA VOL.2 NO.2, 1 Desember 2017, 67-82

Data-data yang terkumpul diolah dengan cara melakukan perhitungan dan penggambaran (deskripsi) yang diperlukan dengan menggunakan metode 8 Step troubleshooting. Proses Diagnosa harus terorganisasi, menggunakan metode -metode yang logis untuk mengidentifkasi dan memecahkan masalah. Hal ini merupakan critical skill bagi seorang technician dan mencerminkan keefektifan dan efisiensi dalam memperbaiki system atau komponen pada engine. Selain itu, akan membantu kemampuan untuk menentukan akar permasalahan dengan cepat dan tepat bagi technician sehingga lebih hemat waktu, energi dan biaya.

1. Pada Langkah diagnosis, terdapat delapan langkah dasar yang harus diikuti berurutan, sebagai berikut:Yakinkan apakah problemnya benar-benar terjadi
a) Kumpulkan semua informasi
b) Komplain dari customer:
c) Apa yang terjadi ?
d) Apa yang sudah dilakukan selama problem terjadi ?
e) Apakah semua sistem yang lain bekerja dengan baik?

2. Tetapkan problem dengan cara menulis /membuat daftar
a) Kumpulkan fakta yang ada
b) Analisa keterangan atau informasi yang ada
c) Kondisi operasi
d) Struktur geografi ? (berbatu, berpasir, dataran tinggi dll)
e) Bagaimana kondisi cuaca? (sangat dingin, sangat panas, kelembaban tinggi, dll)
f) Apakah unit dioperasikan oleh operator yang berpengalaman?
g) Histori dari mesin:Kapan preventive maintenance dilaksanakan?
h) Perbaikan apa saja yang telah dilakukan sebelumnya? 
i) Cek SIRS dan SIS yang paling update.

3. Inspeksi secara visual pada engine atau machine

a) Kumpulkan informasi tambahan yang diperlukan:

b) Lakukan pengecekan secara visual dengan melihat,merasakanmendengarkan,me nyentuh atau dengan penciuman.

c) Lakukan pengetesan teknis, prosedur operasi standar dan juga teknikal prosedur.

d) Gunakan referensi misalnya service manual, buletin dll.

e) Pendukung teknik misalnya supplier ataupun pabrikan

f) Yakinkan problem yang ada dengan cara mengoperasikan mengumpulkan buktibukti yang ada

4. Buat daftar terhadap kemungkinan penyebab kerusakan

a) Identifikasi kerusakan-kerusakan yang mungkin terjadi

b) Identifikasi sebanyak-banyaknya kemungkinan penyebab kerusakan.

c) Jika tidak jelas apa kemungkinan penyebab kerusakan, batasi problem tsb dalam suatu sub-sistem dan coba kembali identifikasi penyebabnya .

d) Kumpulkan lebih banyak informasi terhadap kemungkinan kerusakan yang sulit untuk diidentifikasi.

e) Berpikir logis terhadap fakta yang ada

f) Analisa bukti-bukti yang ada

g) Buatlah daftar terhadap kemungkinan penyebab kerusakan yang potensial

5. Lakukan pengetesan dan catat semua data

a) Cek semua kemungkinan kerusakan: Kumpulkan informasi tambahan untuk pengecekan kemungkinan- kemungkinan kerusakan yg terjadi.

b) Variasikan satu hal setiap kali pengetesan untuk mencari kemungkinan penyebabnya kalau tidak familier dengan system atau alat tsb. 
c) Jika tes yg akan dilakukan memakan banyak waktu atau banyak biaya, coba eliminasi sebanyak mungkin kemungkinan penyebab setiap kali tes dilakukan (gunakan strategi bagi dua).

d) Jangan berasumsi bahwa part baru selalu bagus.

e) Eliminasi kemungkinan-kemungkinan penyebab kerusakan dengan pendekatan secara sistematik.

f) Selalu kembalikan system ke konfigurasi awal setelah penggantian part atau melakukan tes

g) Operasikan alat sendiri untuk mengecek akurasi dari informasi yang anda dapatkan.

h) Minta operator untuk memberikan atau melakukan kembali keadaan pada saat terjadi problem.

i) Buat catatan hasil tes, part yang diganti, dan adjustment yang dilakukan.

j) Selalu ikuti peraturan safety.

6. Temukan akar masalah (eliminasi semua yang tidak mungkin menyebabkan problem)

a) Persempit daftar penyebab kerusakan.

b) Tentukan akar masalah dari problem tsb.

\section{Perbaiki Kerusakan}

a) Catatlah hasil pengujian part yang digunakan dan penyetelan yang dilakukan.

b) Patuhi aturan-aturan keselamatan selama proses perbaikan

8. Analisa mengapa problem terjadi

a) Periksa setiap solusi yang didapat dengan pengujian

b) Bila kerusakan masih muncul setelah melakukan pengujian terhadap solusi (atau muncul problem baru ) lakukan prosedur troubleshooting

c) Isi fault analysis paperwork dan buatkan service report [1] 


\section{HASIL DAN PEMBAHASAN}

\section{Daily Log Oil Consumption}

Dibawah ini adalah daily log yang di report oleh PT KBK selama bulan Januari 2015 Agustus 2015 pada unit EX_011 (DFM00906).

Tabel 2. Daily log oil consumption

\begin{tabular}{|c|c|c|c|}
\hline Month & $\begin{array}{l}\text { Fut Addition } \\
\text { (Liter) }\end{array}$ & $\begin{array}{l}\text { Oil } \\
\text { Addition } \\
\text { Liter) }\end{array}$ & $\begin{array}{l}\text { Of Consumprion(Liter } \\
\text { fuel / Liter oil) }\end{array}$ \\
\hline Februsin & 7368 & 1 & 7568 \\
\hline Maret & 8193 & 10 & 819.3 \\
\hline Apnil & 8561 & 0 & 8561 \\
\hline Mei & 8979 & 815 & 179 \\
\hline Jun & 8040 & 119 & 68 \\
\hline Juili & 10102 & 58 & 174 \\
\hline Agustus & 10733 & 38 & 282 \\
\hline September & 10260 & 37 & 277 \\
\hline Total & 72436 & 344.5 & \\
\hline Ratzrata & & & 210.3 \\
\hline
\end{tabular}

Sumber: Daily Log oil PT.Kasongan Bumi Kencana

\section{Report Grafik Oil Consumtion}

Apabila data di atas dibuat dalam sebuah grafik maka terlihat seperti gambar 2. 
sjme KINEMATIKA VOL.2 NO.2, 1 Desember 2017, 67-82

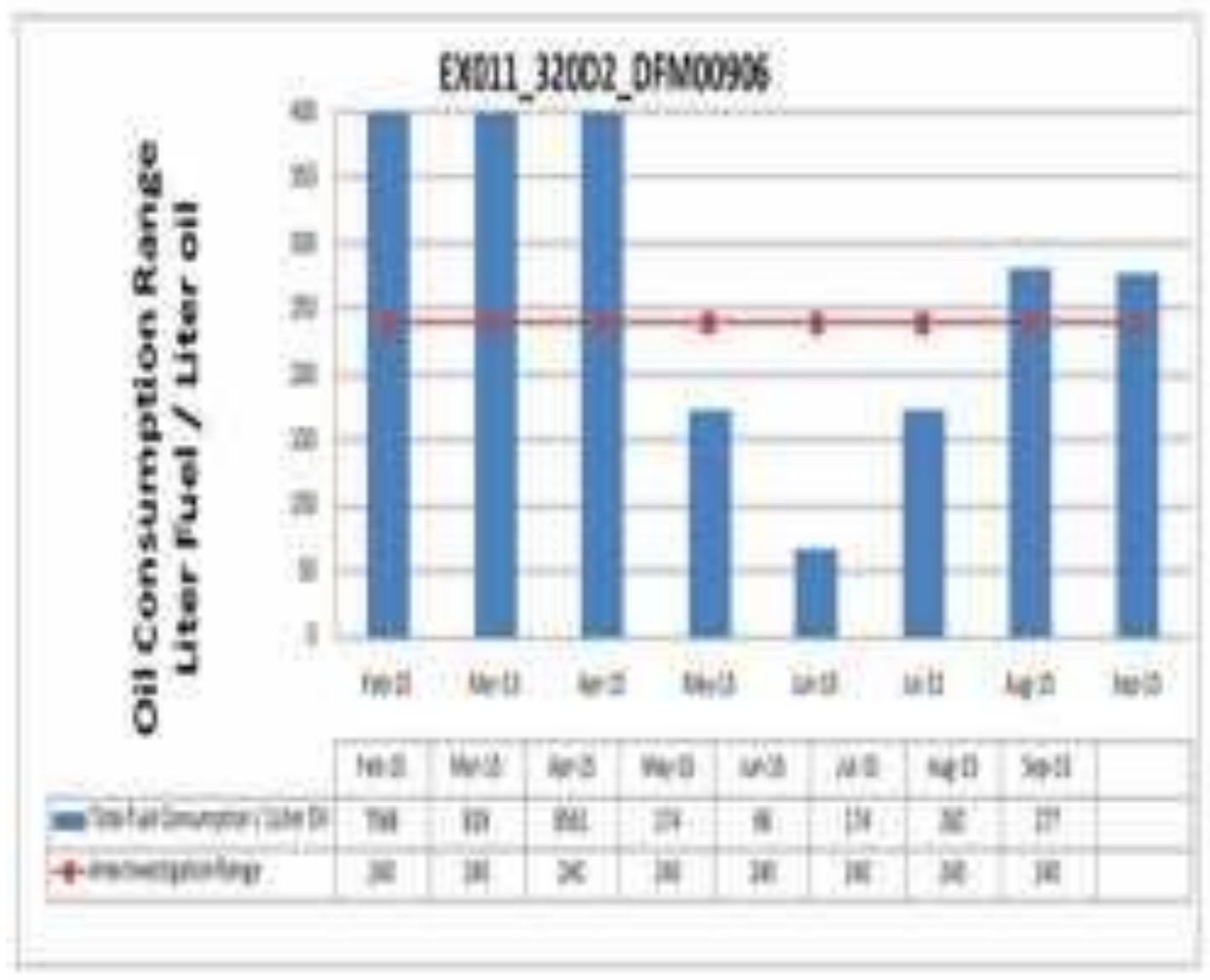

Gambar 2. Grafik Oil Consumtion 


\section{Pencatatan Permasalahan}

Dibawah ini adalah informasi Data unit tentang kondisi unit yang akan dilakukan pemeriksaan:

Tabel 3. Data unit EX 011

\begin{tabular}{|c|c|}
\hline \multicolumn{2}{|c|}{ Dup Unit $E X$ 011 (DFMODSDS) } \\
\hline hame Woder & Casongr Enam whe \\
\hline Equpmen Nimber & EX 910 \\
\hline Hous MGer: & 3405: \\
\hline Hatine Sh & DFHOOBS5 \\
\hline Aamphnent & $4 b 5.0931$ \\
\hline Eghe Stodel & C7 \\
\hline ombine hume & PT KBK \\
\hline $\sin$ & Wrabanocan \\
\hline genatg Lhi & Mang sod \\
\hline Foblen & Hob co hombton \\
\hline
\end{tabular}

\section{Pemeriksaan unit secara visual.}

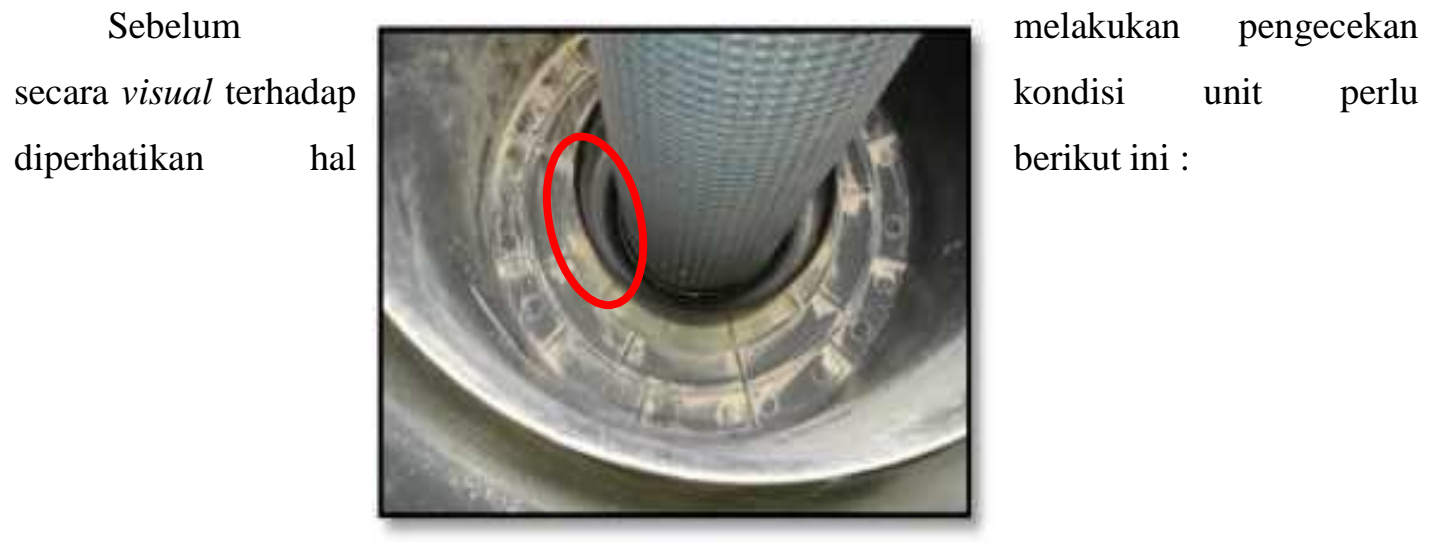

Gambar 3. Pemeriksaan Unit Secara Visual 
sjme KINEMATIKA VOL.2 NO.2, 1 Desember 2017, 67-82

\section{Penyebab Masalah.}

Untuk menentukan kemungkinan penyebab terjadinya kerusakan dapat menggunakan panduan prosedur 8 trouble shooting pada service manual, beberapa problem bisa saja terjadi tidak ada pada panduan trouble shooting, maka diperbolehkan untuk menambah penyebab kerusakan secara logis ataupun berdasarkan pengalaman. Adapaun kemungkinan masalah yang terjadi adalah :

1. Kebocoran oli

2. Level oli

3. Air induction system

4. Turbocharger

5. Internal Engine wear

\section{Test dan Record data}

Untuk melakukan test mulailah dari hal yang lebih mudah dahulu :

\section{Akar Permasalahan}

Dari hasil pengecekan pada step 5 dapat disimpulkan yang menjadi sumber permasalahan adalah dari system pemasukan udara yang tidak baik. Machine EX_011 (DFM00906) mulai dari tidak memasang secondary air filter dan pemasangan part yang salah, dibuktikan bahwa ditemukannya banyak debumulai dari saluran air cleaner sampai dengan saluran intake manifold, hal itu dapat menyebabkan kontaminasi pada saat pembakaran. 

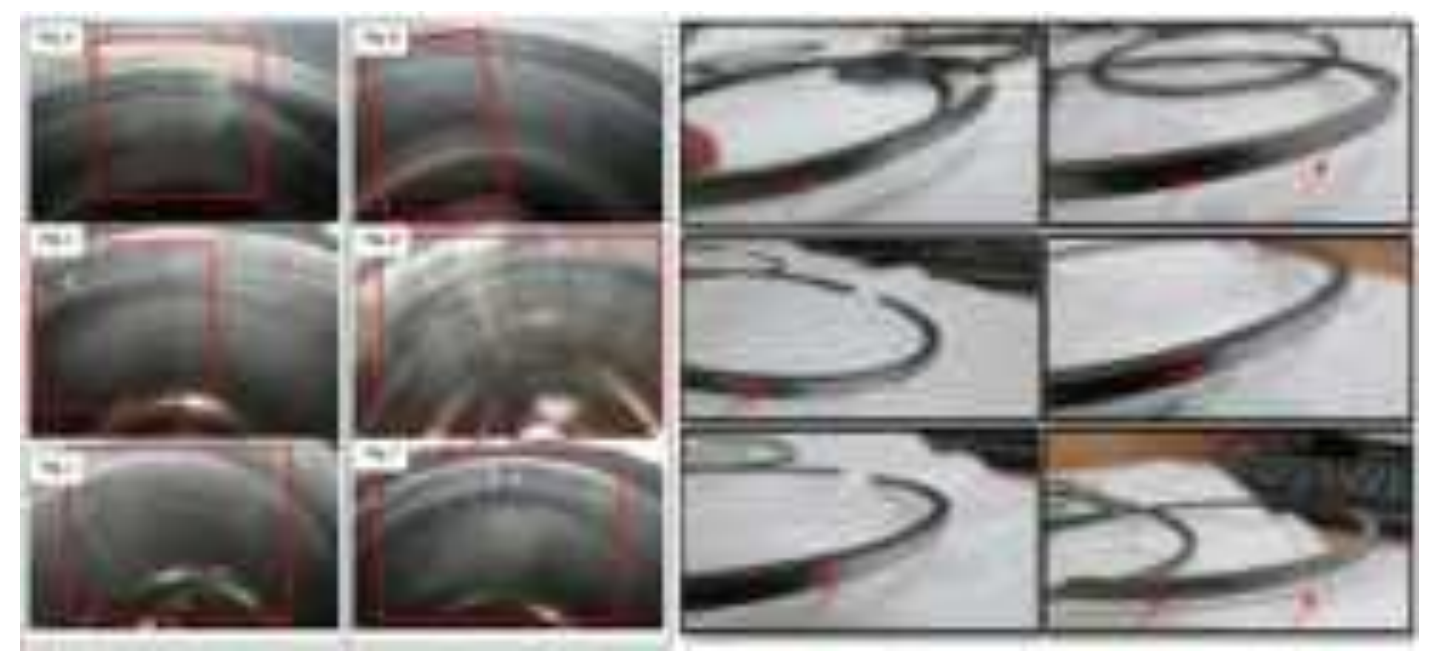

Gambar 4. Akar Pemasalahan

\section{Perbaiki Kerusakan}

Engine dibawa ke workshop PT Trakindo Utama Banjarmasin untuk dilakukan pemeriksaan lebih lanjut di workshop PT Trakindo Utama Banjarmasin

\section{Analisa Kerusakan}

Unit Excavator 320D EX_011 (DFM00906) beroperasi di area gold mining dengan kondisi udara yang sangat berdebu. Saat unit beroperasi dengan menggunakan secondary air filter tapi dengan part number yang tidak tepat EX_011(DFM00906) memungkinkan debu masuk kedalam engine sistem. Saat engine running, debu tersebut menjadi kontaminan yang menyebabkan terjadinya friction/gesek anantara permukaan liner dan ring piston. Kondisi tersebut mengakibatkan premature wear pada komponen. Ring piston aus dan liner juga mengalami keausan, keausan liner EX_011 sebesar 0.003 dimana terlihat pada cross pattern yang sudah tidak tampak, keausan tersebut

\section{Proses Maintenance}

Dengan melihat hasil dari analisa menggunakan 8 step troubleshooting didapatkan bahwa penyebab utama menigkatnya pemakaian oli engine C7 Excavator 320D Caterpillar disebabkan oleh penggunaan secondary filter yang tidak sesuai dengan Standar dari 
sjme KINEMATIKA VOL.2 NO.2, 1 Desember 2017, 67-82

unit tersebut maka proses maintenance yang dilakukan haruslah sesuaidengan OMM (Operation Maintenance manual)

\section{Kerugian Akibat Meningkatnya Pemakaian Oli}

Engine EX_011 DFM00906 pada hours meter 2930.5 telah mengalami masalah yang menyebabkan engine harus dilakukan pembongkaran akibat pemasangan secondary air filter yang tidak sesuai dengan part number dari unit tersebut. Jika saja engine dilakukan sesuai dengan prosedur maka estimasi engine untuk dilakukan jadwal overhaul berada pada Hours meter 12000 jam.

Berikut perhitungan kerugian yang dialami akibat peningkatan oli yang meningkat akibat kesalahan menggunakan part yang tidak sesuai.

$$
\begin{aligned}
& \text { Oll usage Nomal }=\frac{\text { Fuel usage actual }}{\text { OAlConsumption Normal }} \\
& \begin{aligned}
\text { OH Usage Nomal } & =\frac{72436 \text { Iiter }}{240 \text { Iter }} \\
& =301 \text { liter }
\end{aligned}
\end{aligned}
$$

Keterangan :

Oil usage normal $=$ pemakaian Oli dalam kondisi normal

Fuel usage actual $=$ jumlah pemakaian oli

secara keseluruhan

mulai bulan Februari-September 
Oil comsumption normal $=$ jumlah standar konsumsi bahan bakar utk penambahan 1 liter oli

Tabel. 4. Kerugian Pemakaian Oli

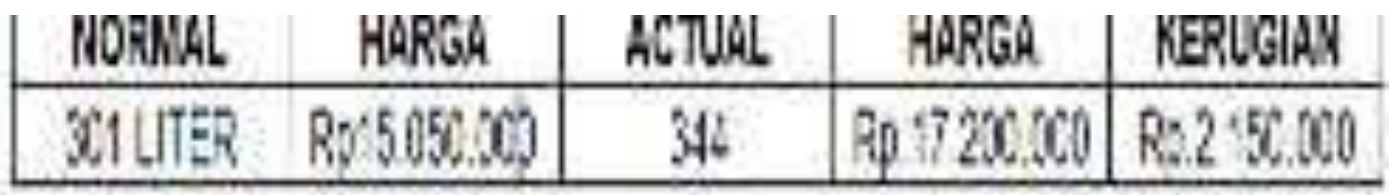

Dari table diatas dapat diketahui bahwa untuk pemakaian oli dalam kondisi normal 301 liter dimana untuk harganya sebesar Rp. 15.050.000, dan kondisi actual engine dengan kondisi yang tidak normal (unit EX 011) didapatkkan sebesar 344 liter dengan harga Rp. 17.200.000, jadi biaya kerugian akibat penambahan oli yang tidak sesuai dengan standar engine C7 pada Unit EX 011 sebesar Rp. 2.250.000. *harga Oli Engine CAT SAE 15W/40 1 drum/200liter; Rp 10.000.000. Setelah diketahui kerugian akibat pemakaian oli maka dapat direkapitulasi kerugian engine C7 Excavator 320D Caterpillar (EX 011) seperti pada table di bawah ini :

Tabel 5. Kerugian Engine C7 Excavator 320 Caterpillar (ex 011)

\begin{tabular}{|c|c|}
\hline \multicolumn{2}{|r|}{ RERUALAR LWIT EX O11 } \\
\hline RETEAMWGAN & MERUGIAH \\
\hline of & $\mathrm{Ap}=10000$ \\
\hline PHSI & Ap touser ass $t$ \\
\hline LAOS & Ap. Ge 70060000 \\
\hline WSCELLALOUS & Rp 19.480505 .25 \\
\hline TOTAL & RPR200.060.699+PFA10\% - RP.300.006.769 \\
\hline
\end{tabular}


sjme KINEMATIKA VOL.2 NO.2, 1 Desember 2017, 67-82

biaya keseluruhan kerugian unit EX 011 milik PT Kasongan Bumi Kencana akibat meningkatnya pemakaian oli yang disebabkan penggunaan part yang tidak sesuai sebesar Rp.309.056.768

\section{KESIMPULAN}

1. Setelah dilakukan analisa 8 step troubleshooting diketahui penyebab meningkatnya pemakaian oli yang berlebihan di karenakan pemakaian air cleaner tidak sesuai dengan OMM (Operational Manual Maintenance yang berlaku

2. Setelah melakukan 8 step troubleshooting ditemukan dampak dari meningkatnya pemakaian oli yang mana Kondisi tersebut mengakibatkan premature wear pada komponen

3. Biaya perbaikan pada engine yang mengalami high oil consumption sebesar Rp.309.056.768

\section{REFERENSI}

1. Centre, Training. (2012). Engine PerformanceAnalysis. Cileungsi, Bogor : Training Centre.

2. Centre, Training. (2003). Engine Rebuild. Cileungsi, Cileungsi, Bogor: Training Centre.

3. Centre, Training. (2003). Diesel Engine Fundamental. Cileungsi, Bogor: Training Centre.

4. Centre,Training.(2012).BasicPreventive Maintenance. Cileungsi, Bogor : Training Centre.

5. Centre,Training.(2013)8 StepTroubleShootig Method. Cileungsi, Bogor:Training Centre.

6. SIS (Service Information System). 2011. B:Illionis: United States 